Discussion Paper No. 776

\title{
EVOLUTION OF COMPETITIVE EQUILIBRIUM WITH ENDOGENOUS PRODUCT DIFFERENTIATION
}

\author{
Toshihiro Matsumura \\ Noriaki Matsushima \\ Tetsuo Yamamori
}

May 2010

The Institute of Social and Economic Research

Osaka University

6-1 Mihogaoka, Ibaraki, Osaka 567-0047, Japan 


\title{
Evolution of Competitive Equilibrium with Endogenous Product Differentiation
}

\author{
Toshihiro Matsumura \\ Institute of Social Science, University of Tokyo \\ Noriaki Matsushima \\ Institute of Social and Economic Research, Osaka University \\ Tetsuo Yamamori* \\ Department of General Education, Gunma National College of Technology
}

May 21, 2010

\begin{abstract}
Previous theoretical researches show that learning from good performers yields intense competition and results in the low profitability of firms. These researchers do not take into account differentiation strategies being referred as a useful strategic tool to mitigate competition. We introduce an evolutionary (learning) game into a duopoly model with product differentiation on the Hotelling line. We find that central agglomeration appears in the unique stochastically stable state in which the equilibrium price is equal to the marginal cost of firms. This implies that perfectly competitive equilibrium appears even when firms have an opportunity to differentiate themselves through product differentiation and to mitigate competition.
\end{abstract}

JEL classification: C73, D41, D43, R32

Key words: product positioning, two dimensional choice, Walrasian, evolutionally stable, spatial agglomeration.

\footnotetext{
${ }^{*}$ Corresponding author: Tetsuo Yamamori, Gunma National College of Technology, 580, Toriba, Maebashi, Gunma, 371-8530, Japan phone: +81-27-254-9100, fax: +81-27-254-9022, email:yamamori@gen.gunma-ct.ac.jp
} 


\section{Introduction}

Learning from good performers seems to be a reasonable strategy to improve performance in many situations. For instance, firms often adopt a "me-too" strategy by following market leaders. In the literature of evolutionary learning, however, this "me-too" strategy often leads to low performance under strategic environments. For instance, Vega-Redondo (1997) investigates a Cournot model where firms learn through the imitation of success and shows that Walrasian equilibrium appears in the unique stochastically stable state. ${ }^{1}$ That is, each firm equates its marginal cost to the market price (price taking behavior) in the stable state. This outcome, obviously, means that each firm's performance is low from the viewpoint of profitability. To escape this kind of fierce competition, we need to note that product differentiation is an important strategic tool of firms. ${ }^{2}$ When firms can choose their product positions endogenously, are they able to differentiate their products by the imitation of success? We show that the answer is "No".

In this paper, we introduce an evolutionary game into an endogenous product differentiation model where firms compete in terms of price and product position on the Hotelling line. We adopt the idea of Vega-Redondo (1997) and investigate the stochastically stable state in the dynamic stochastic framework. We find that central agglomeration (no product differentiation) appears in the unique stochastically stable state. At the equilibrium, the price is equal to the marginal cost of firms. The competitive equilibrium appears in the long run even when firms

\footnotetext{
1 Starting with the analysis of Vega-Redondo (1997), evolution dynamics have been applied to Cournot oligopolies (Schenk-Hoppé (2000), Alós-Ferrer (2004), Alós-Ferrer and Ania (2005), Schipper (2009)); Bertrand oligopolies (Alós-Ferrer et al. (2000), Hehenkamp (2002), Ania (2008)); and differentiated product oligopolies (Tanaka $(2000,2001)$ and Tasnádi (2006)).

${ }^{2}$ Since the seminal work of Hotelling (1929), the spatial model has become one of the most important methods of analyzing product differentiation. For instance, d'Aspremont et al. (1979) formulate a two-stage location-price game on the Hotelling line. They show that the products are maximally differentiated under quadratic transport costs. As a result, the equilibrium prices exceed marginal costs; this is unlike in a perfectly competitive equilibrium.
} 
have an opportunity to differentiate themselves through product differentiation and to relax the competition. This is quite different from the results in the literature on spatial models with price competition. Some researchers have already attempted to explain central agglomeration. de Palma et al. (1985) show that sufficient heterogeneity between firms induces central agglomeration. Price collusion after firms have made location choices is considered in Friedman and Thisse (1993) and Jehiel (1992). Cooperation between firms is considered in the form of information exchange through communication by Mai and Peng (1999). In all works, the equilibrium outcomes are not Walrasian.

Our result strengthens the result of Vega-Redondo (1997). As mentioned above, he investigates a quantity competition in homogeneous product markets and shows that the Walrasian equilibrium appears in the unique stochastically stable state where each firm equates its marginal cost with the market price (price taking behavior). This result is in sharp contrast to the Cournot limit theorem since his result holds true as long as the number of firms is equal or more than two. However, his result depends on the assumption of homogeneous product markets. If products are differentiated, the equilibrium prices exceed marginal costs. Our result indicates that his result is quite robust and his basic principle is applicable to broader situations. Firms dare not differentiate their products in the unique stable state.

The remainder of this paper is organized as follows. Section 2 formulates the model. Section 3 presents the main result. Section 4 includes the concluding remarks.

\section{The Model}

\subsection{Location and Price Competition}

Consider a model of differentiation on the Hotelling (1929) line. A linear city of length 1 lies on the abscissa of a line, and consumers are uniformly distributed with density 1 along this interval. There are two firms, and each of them locates at some point in the city and sells the 
same physical product. When a consumer moves a distance $d$ to buy the product, he/she incurs a transportation cost $t(d)$. We assume that $t(d)$ is continuous, strictly increasing, and strictly convex. ${ }^{3}$ Each consumer buys one unit if and only if the minimum generalized price (price plus transportation cost) for the two firms does not exceed $u$, the reservation value of the product.

Two firms compete in terms of their locations and prices. Each firm chooses its price from a common countable set $P=\{\delta, 2 \delta, \ldots, v \delta\}$, where $\delta>0$ and $v$ is a positive integer. To simplify the analysis, we assume that $u-t(1 / 2)>v \delta$. Firm 1 locates at a point in the left-side of the city and firm 2 locates at a point in the right-side of the city. Each firm chooses how far it locates from the center of the city. The set of locations of each firm is given as $A=\{0,1 / n, 2 / n, \ldots, 1\}$, where $n$ is a positive integer. When firm 1 (firm 2) chooses action $a_{1}\left(a_{2}\right) \in A$, it is located at $\left(1-a_{1}\right) / 2\left(\left(1+a_{2}\right) / 2\right)$. A strategy $s_{i}$ of firm $i$ identifies its price and location. Both firms have the same strategy set $S=A \times P$.

Given a strategy profile $\left(s_{1}, s_{2}\right)=\left(\left(a_{1}, p_{1}\right),\left(a_{2}, p_{2}\right)\right)$ where $a_{i} \neq 0$ for some $i$, let $x\left(s_{1}, s_{2}\right)$ be a real number satisfying

$$
p_{1}+t\left(\left|\frac{1}{2}\left(1-a_{1}\right)-x\left(s_{1}, s_{2}\right)\right|\right)=p_{2}+t\left(\left|\frac{1}{2}\left(1+a_{2}\right)-x\left(s_{1}, s_{2}\right)\right|\right) .
$$

If $0 \leq x\left(s_{1}, s_{2}\right) \leq 1$, it is the location of the consumer who is indifferent as to from where he/she buys the product. For a strategy profile $\left(s_{1}, s_{2}\right)=\left(\left(a_{1}, p_{1}\right),\left(a_{2}, p_{2}\right)\right)$ where $a_{i} \neq 0$ for some $i$, the demand $X_{1}\left(s_{1}, s_{2}\right)$ for firm 1 is given by

$$
X_{1}\left(s_{1}, s_{2}\right)= \begin{cases}0 & \text { if } x\left(s_{1}, s_{2}\right)<0 \\ x\left(s_{1}, s_{2}\right) & \text { if } 0 \leq x\left(s_{1}, s_{2}\right) \leq 1 \\ 1 & \text { if } 1<x\left(s_{1}, s_{2}\right)\end{cases}
$$

For a strategy profile $\left(s_{1}, s_{2}\right)=\left(\left(a_{1}, p_{1}\right),\left(a_{2}, p_{2}\right)\right)$ where $a_{1}=a_{2}=0$, the demand for firm 1 is

\footnotetext{
${ }^{3}$ The assumption of convexity of the transport cost is just for simplicity. Our theorem holds even without this assumption.
} 
given by

$$
X_{1}\left(s_{1}, s_{2}\right)= \begin{cases}0 & \text { if } p_{1}>p_{2} \\ 1 / 2 & \text { if } p_{1}=p_{2} \\ 1 & \text { if } p_{1}<p_{2}\end{cases}
$$

The demand $X_{2}\left(s_{1}, s_{2}\right)$ for firm 2 is given by $\left(1-X_{1}\left(s_{1}, s_{2}\right)\right)$. The payoffs of the firms 1 and 2 are given by $\pi_{1}\left(s_{1}, s_{2}\right)=p_{1} X_{1}\left(s_{1}, s_{2}\right)$ and $\pi_{2}\left(s_{1}, s_{2}\right)=p_{2} X_{2}\left(s_{1}, s_{2}\right)$, respectively.

Lemma 1. Given a strategy profile $\left(s_{1}, s_{2}\right)=\left(\left(a_{1}, p_{1}\right),\left(a_{2}, p_{2}\right)\right)$,

(i) if $p_{1}=p_{2}$ and $a_{j}>a_{i}$, then $\pi_{i}\left(s_{1}, s_{2}\right)>\pi_{j}\left(s_{1}, s_{2}\right)$,

(ii) if $p_{j}>p_{i}$ and $a_{1}=a_{2}=0$, then $\pi_{i}\left(s_{1}, s_{2}\right)>\pi_{j}\left(s_{1}, s_{2}\right)$.

Hotelling has already shown a result similar to Lemma 1(i). If both firms name the same price, the firm closer to the central point obtains a larger market share, which results in higher profits for that firm. Lemma 1(ii) discusses the case with no product differentiation. Without product differentiation, the firm naming a higher price obtains zero market share, which results in zero profits.

\subsection{Imitation Dynamics}

Evolutionary dynamics are taken to proceed in discrete time, which is indexed by $t=0,1,2, \ldots$. At each $t$, the state of the system may be identified using $s^{t}=\left(s_{1}^{t}, s_{2}^{t}\right)=\left(\left(a_{1}^{t}, p_{1}^{t}\right),\left(a_{2}^{t}, p_{2}^{t}\right)\right)$. Thus, the state space of the system is the set of strategy profiles $\Theta=S^{2}$. Associated to any such $s^{t}$, the induced profit $\pi^{t}=\left(\pi_{1}^{t}, \pi_{2}^{t}\right)$ is defined by $\pi_{i}^{t}=\pi_{i}\left(s^{t}\right)$ for each $i$. At every time $t$, each firm is assumed to enjoy a common and independent probability $r>0$ of being able to revise its former strategy. When firm $i$ revises its strategy, it imitates firm $j$ 's strategy if the payoffs of $j$ are higher than those of $i$. Otherwise, it continues with its earlier strategy. ${ }^{4}$ This

\footnotetext{
${ }^{4}$ Our results hold true even if the revision probabilities of location and price are different as long as the revision occurs at the same time with a positive probability.
} 
imitation process defines a Markov process $T_{0}=\left\{T_{0}\left(s, s^{\prime}\right)\right\}_{s, s^{\prime} \in \Theta}$ on the state space $\Theta$, where $T_{0}\left(s, s^{\prime}\right)$ is a transition probability from $s$ to $s^{\prime}$.

A nonempty set $Q \subseteq \Theta$ is absorbing if $T_{0}\left(s, s^{\prime}\right)=0$ for all $s \in Q$ and $s^{\prime} \notin Q$, and no proper subset of $Q$ has this property. The basin of attraction of an absorbing set $Q$ is the set of states from which there exists a positive probability that the imitation process moves the system to $Q$ in finite time.

It is evident that any state $s$ where $\pi_{i}=\pi_{j}$ constitutes a singleton absorbing set. Note that if $\pi_{i}>\pi_{j}$, the event that firm $j$ imitates firm $i$ occurs with a positive probability. Thus, from any state with $\pi_{i} \neq \pi_{j}$, there exists a positive probability that the imitation process moves the system to a singleton absorbing set in which the two firms have the same payoffs.

Lemma 2. (i) For any state $s$ such that $\pi_{i}(s) \neq \pi_{j}(s)$, there exists an absorbing set $\{\theta\}$, whose basin of attraction contains $s$.

(ii) It follows from (i) that any absorbing set is a singleton in which the payoffs of the two firms are the same.

Hereafter, an absorbing set is referred to as an absorbing state.

\subsection{Mutations}

At the end of each period $t$, the price and location of each firm mutate by a common independent probability $\epsilon>0$. In this event, all of the prices or all of the locations are chosen with a positive probability. Note that the probability of mutating both price and location of a firm is $\epsilon^{2}$. It is crucial for this paper that two or more mutations are required for a price and location to change simultaneously. An interpretation of this mutation process is as follows. There are two managers in each firm: a pricing manager who decides the firm's price and a location manager who decides the firm's location. With a small probability, each manager experiments with new choices or is replaced by a new manager. 
The imitation process with mutations defines a Markov process $T_{\epsilon}=\left\{T_{\epsilon}\left(s, s^{\prime}\right)\right\}_{s, s^{\prime} \in \Theta}$ on the state space $\Theta$, where $T_{\epsilon}\left(s, s^{\prime}\right)$ is a probability that the combination of the imitation and mutation processes moves the system from $s$ to $s^{\prime}$. Note that $T_{\epsilon}\left(s, s^{\prime}\right)>0$ for all $s, s^{\prime} \in \Theta$. Since all elements in $T_{\epsilon}$ are strictly positive, $T_{\epsilon}$ is irreducible and aperiodic. Therefore, $T_{\epsilon}$ has the following properties: ${ }^{5}$ (i) there exists a unique stationary distribution $\mu_{\epsilon}^{*}$ satisfying $\mu_{\epsilon}^{*} T_{\epsilon}=\mu_{\epsilon}^{*}$; (ii) the system converges to $\mu_{\epsilon}^{*}$ from any initial condition; (iii) in any sufficiently lengthy time period, the cumulative relative frequency of the time the system spends on each state is approximately given by $\mu_{\epsilon}^{*}$; (iv) the limiting distribution, $\lim _{\epsilon \rightarrow 0} \mu_{\epsilon}^{*}$, exists.

A state in support of the limiting distribution is known as a stochastically stable state in Young (1993). When the mutation rate is small, the system spends most of the time in stochastically stable states.

\section{Results}

\subsection{Existing results}

In order to investigate stochastically stable states, we rely on the mutation-counting arguments employed by Kandori et al. (1993) and Young (1993). For each $s \in \Theta$, a $s$-tree $h$ is a binary relation on $\Theta$ such that (i) for every state $s^{\prime} \in \Theta \backslash\{s\}$, there exists one and only one transition of the form $\left(s^{\prime} \rightarrow s^{\prime \prime}\right)$; (ii) from every state $s^{\prime} \in \Theta \backslash\{s\}$, there exists a sequence of the form $\left(s^{\prime} \rightarrow k^{1}\right),\left(k^{1} \rightarrow k^{2}\right), \ldots,\left(k^{l} \rightarrow s\right)$; (iii) there exists no transition of the form $\left(s \rightarrow s^{\prime}\right)$.

The cost $\psi\left(s, s^{\prime}\right)$ of the transition of the form $\left(s \rightarrow s^{\prime}\right)$ is defined by the least number of mutations required to move the system from $s$ to $s^{\prime}$. Note that for any absorbing state $\theta$, $\psi(\theta, s) \geq 1$ for any $s \in \Theta \backslash\{\theta\}$, since it takes at least one mutation to move from any absorbing state. On the other hand, for any non-absorbing state $s$, there is an absorbing state $\theta$ with $\psi(s, \theta)=0$.

\footnotetext{
${ }^{5}$ See Freidlin and Wentzel (1984).
} 
The cost of a tree $h$ is given by $\sum_{\left(s \rightarrow s^{\prime}\right) \in h} \psi\left(s, s^{\prime}\right)$. It is well known that state $s$ is a stochastically stable state if and only if the minimum cost among all $s$-trees is also the minimum among all states in $\Theta$. We now claim the following lemma without proof.

Lemma 3. State $s^{*}$ is a stochastically stable state if and only if

$$
s^{*} \in \arg \min _{s \in \Theta}\left(\min _{h \in H_{s}} \sum_{\left(s \rightarrow s^{\prime}\right) \in h} \psi\left(s, s^{\prime}\right)\right),
$$

where $H_{s}$ is the set of $s$-trees.

It is easy to see that $s^{*}$ is a stochastically stable state only if it is an absorbing state.

\subsection{Stochastically stable state}

Let $\theta^{*}=\left(\left(a_{1}^{*}, p_{1}^{*}\right),\left(a_{2}^{*}, p_{2}^{*}\right)\right)$ be an absorbing state, where $a_{1}^{*}=a_{2}^{*}=0$ and $p_{1}^{*}=p_{2}^{*}=\delta$. The following lemma implies that $\theta^{*}$ is a stochastically stable state.

Lemma 4. There exists a $\theta^{*}$-tree $h$ whose cost is exactly $\lambda-1$, where $\lambda$ is the number of absorbing states.

Proof. Consider a $\theta^{*}$-tree $h$ that satisfies the following conditions. (1) For any absorbing state $\theta=\left(s_{1}, s_{2}\right)$ with $s_{1} \neq s_{2}, h$ contains the transition of the form $\left(\theta \rightarrow \theta^{\prime}\right)$, where $\theta^{\prime}=((a, p),(a, p))$ and $\psi\left(\theta, \theta^{\prime}\right)=1$. (2) For any absorbing state $\theta=((a, p),(a, p))$ with $a \neq 0, h$ contains $\left(\theta \rightarrow \theta^{\prime}\right)$, where $\theta^{\prime}=((0, p),(0, p))$. (3) For any absorbing state $\theta=((0, p),(0, p))$ with $p \neq \delta, h$ contains $\left(\theta \rightarrow \theta^{*}\right)$. (4) For any non-absorbing state $s, h$ contains $(s \rightarrow \theta)$ such that $s \in B(\theta)$.

Note that in any absorbing state $\theta=\left(s_{1}, s_{2}\right)$ with $s_{1} \neq s_{2}, \pi_{1}\left(s_{1}, s_{2}\right)=\pi_{2}\left(s_{1}, s_{2}\right)$ by Lemma 2 (ii). Note also that the payoffs of two firms will differ if at least one mutation occurs. Therefore, by Lemma 2 (i), there exists an absorbing state $\theta^{\prime}=((a, p),(a, p))$ with $\psi\left(\theta, \theta^{\prime}\right)=1$. Thus, we can construct a tree $h$ that satisfies condition (1). Furthermore, it follows from Lemma 1 that the cost of each transition that appeared in the conditions (2) and (3) is 1. Therefore, the cost of the above tree is exactly $\lambda-1$. 
Lemma 5. For any absorbing state $\theta \neq \theta^{*}$, the cost of any $\theta$-tree $h$ is larger than $\lambda-1$.

Proof. We show that more than one mutation is required for going from $\theta^{*}$ to any other absorbing state. Consider a state $s=\left(\left(a_{1}^{*}, p_{1}^{\prime}\right),\left(a_{2}^{*}, p_{2}^{*}\right)\right)$, where $p_{1}^{\prime} \neq p_{1}^{*}$. Since $p_{1}^{\prime}>p_{2}^{*}=\delta, \pi_{2}(s)>\pi_{1}(s)$ by Lemma 1 (ii). Therefore, from state $s$, the imitation process without mutations converges to $\theta^{*}$. Next, consider a state $s=\left(\left(a_{1}^{\prime}, p_{1}^{*}\right),\left(a_{2}^{*}, p_{2}^{*}\right)\right)$, where $a_{1}^{\prime} \neq a_{1}^{*}$. Since $a_{1}^{\prime}>a_{2}^{*}=0$, $\pi_{2}(s)>\pi_{1}(s)$ by Lemma 1 (i). Therefore, from state $s$, the imitation process without mutations converges to $\theta^{*}$. Similarly, the imitation process without mutations converges to $\theta^{*}$ from any state where either the price or the location of firm 2 is not $\theta^{*}$.

Note that the assumption that either a price or a location changes in one mutation is crucial for this Lemma. If a price and a location change simultaneously with probability $\epsilon$, only one mutation may move the system from $\theta^{*}$ to another absorbing state.

Lemmata 4 and 5 imply that $\theta^{*}$ is a unique stochastically stable state. Thus, we have the following theorem.

Theorem . There exists a unique stochastically stable state $\theta^{*}=\left(\left(a_{1}^{*}, p_{1}^{*}\right),\left(a_{2}^{*}, p_{2}^{*}\right)\right)$, where $a_{1}^{*}=a_{2}^{*}=0$ and $p_{1}^{*}=p_{2}^{*}=\delta$.

We now explain the intuition behind the result. In the long run, firms name the same price through the imitation process. Given the common price, the firm located closer to the central point obtains larger profits (Lemma 1(i)). Thus, through the imitation process, the firms agglomerate at the central point.

\section{Concluding Remarks}

In this paper, we investigate evolutional dynamics in an endogenous product differentiation

model. Firms compete in terms of price and location on the Hotelling line. We adopt the idea of Vega-Redondo (1997) and investigate the stochastically stable state in the dynamic stochastic 
framework. We find that firms produce homogeneous products in the unique stochastically stable state. The competitive equilibrium appears in the long-run even when firms have an opportunity to relax the competition through product differentiation.

We adopted the standard assumption of the Hotelling model that each consumer consumes one unit of product. However, our result does not depend on this assumption. Even if we introduce the model of Anderson and de Palma (2000) with elastic demand for each consumer, our result still holds true.

Our result is very closely related to the discussions on the relative payoff approach. ${ }^{6}$ If the firms care more about their relative profits, firms have an incentive to choose smaller product differentiation. Investigating the relationship between the relative profit approach and evolutionary dynamics in more general contexts remains for the future.

\footnotetext{
${ }^{6}$ One of the most fundamental assumptions in economics is that firms maximize absolute profits. However, already Alchian (1950) suggested that firms may maximize relative profits in the long run rather than absolute profits.
} 


\section{References}

A. A. Alchian, Uncertainty, evolution, and economic theory, Journal of Political Economy $\mathbf{5 8 ( 3 ) ( 1 9 5 0 ) , ~ 2 1 1 - 2 2 1 . ~}$

C. Alós-Ferrer, Cournot versus Walras in dynamic oligopolies with memory, International Journal of Industrial Organization 22(2)(2004), 193-217.

C. Alós-Ferrer, and A. B. Ania, The evolutionary stability of perfectly competitive behavior, Economic Theory 26(3)(2005), 497-516.

C. Alós-Ferrer, A. B. Ania, and K. R. Schenk-Hoppé, An evolutionary model of Bertrand oligopoly, Games and Economic Behavior 33(1)(2000), 1-19.

S. P. Anderson and A. de Palma, From local to global competition, European Economic Review 44(3)(2000), 423-448.

A. B. Ania, Evolutionary stability and Nash equilibrium in finite populations, with an application to price competition, Journal of Economic Behavior and Organization 65(3-4)(2008), $472-488$.

C. d'Aspremont, J. J. Gabszewicz, and J. -F. Thisse, On Hotelling's stability in competition, Econometrica 47(5)(1979), 1145-1150.

A. de Palma, V. Ginsburgh, Y. Y. Papageorgiou, and J.-F. Thisse, The principle of minimum differentiation holds under sufficient heterogeneity, Econometrica 53(4)(1985), 767-782.

M. I. Freidlin and A. D. Wentzel, Random Perturbations of Dynamical Systems. New York: Springer Verlag (1984).

J. W. Friedman, and J.-F. Thisse, Partial collusion fosters minimum product differentiation, Rand Journal of Economics 24(4)(1993), 631-645.

B. Hehenkamp, Sluggish consumers: An evolutionary solution to the Bertrand paradox, Games and Economic Behavior 40(1)(2002), 44-76.

H. Hotelling, Stability in competition, Economic Journal 39(153)(1929), 41-57.

P. Jehiel, Product differentiation and price collusion, International Journal of Industrial Organization 10(1992), 633-641.

M. Kandori, G. Mailath, and R. Rob, Learning, mutations, and long-run equilibria in games, Econometrica 61(1)(1993), 29-56. 
C.-C. Mai and S.-K. Peng, Cooperation vs. competition in a spatial model. Regional Science and Urban Economics 29(4)(1999), 463-472.

K. R. Schenk-Hoppé, The evolution of Walrasian behavior in oligopolies, Journal of Mathematical Economics 33(1)(2000), 35-55.

B. C. Schipper, Imitators and optimizers in Cournot oligopoly, Journal of Economic Dynamics and Control 33(12)(2009), 1981-1990.

Y. Tanaka, Stochastically stable states in an oligopoly with differentiated goods: equivalence of price and quantity strategies, Journal of Mathematical Economics 34(2)(2000), 235-253.

Y. Tanaka, Evolution to equilibrium in an asymmetric oligopoly with differentiated goods, International Journal of Industrial Organization 19(9)(2001), 1423-1440.

A. Tasnádi, Price vs. quantity in oligopoly games, International Journal of Industrial Organization 24(3)(2006), 541-544.

F. Vega-Redondo, The evolution of Walrasian behavior, Econometrica 65(2) (1997), 375-384.

P. Young, The evolution of conventions, Econometrica 61(1)(1993), 57-84. 